\title{
An online taxonomic database of the stick insect (Phasmida) egg-parasitising subfamilies Amiseginae and Loboscelidiinae (Hymenoptera: Chrysididae)
}

\author{
Ed Baker $\ddagger$ \\ ‡ The Natural History Museum, London, United Kingdom
}

Corresponding author: Ed Baker (edwbaker@gmail.com)

Academic editor: Michael Engel

Received: 07 Dec 2015 | Accepted: 07 Jan 2016 | Published: 08 Jan 2016

Citation: Baker E (2016) An online taxonomic database of the stick insect (Phasmida) egg-parasitising subfamilies Amiseginae and Loboscelidiinae (Hymenoptera: Chrysididae). Biodiversity Data Journal 4: e7441. doi: $\underline{10.3897 / B D J .4 . e 7441}$

\section{Abstract}

\section{Background}

The wasp subfamilies Amiseginae and Loboscelidiinae (Hymenoptera: Chrysididae) were last catalogued in Kimsey and Bohart (1991). The subfamilies are considered to be obligate egg parasitoids of the Phasmida (stick insects), which are known to be pests in many areas of the world (Baker 2015). Our lack of knowledge of these wasps, in particular their host associations and host specificity, prevents studies into using them as potential control agents for pest phasmids. Phasmids are popular throughout the world with people from a wide range of backgrounds, from pet keepers to professional entomologists.

\section{New information}

A taxonomic database of the subfamilies Amiseginae and Loboscelidiinae has been created as the Chrysididae SpeciesFile, summarising the current state of scientific knowledge about these groups. In addition, a bibliography of works on these subfamilies has been created. In total information is provided for 187 valid species. 


\section{Keywords}

taxonomic database, parasitoid wasp, Phasmida, Phasmatodea, stick insect, Hymenoptera, Chrysididae, Loboscelidiinae, Amiseginae

\section{Introduction}

The Phasmida Species File Online (Brock 2015) has become the defacto online resource for reliable taxonomic information on that order. It is hoped that a creation of a similar database of their predominant egg parasitoids will facilitate new research in this field. The host associations of the Amiseginae and Loboscelidiinae are poorly known. Only 12 unique associations at the species level have been recovered from the literature while developing the current project.

The Phasmida (= Phasmatodea; Phasmatoptera; Cheleutoptera) are large, obligate herbivores (Bedford 1978) that are known as pests of agriculture and forestry in North America, Asia, and Oceania (Baker 2015). The wasp subfamilies Amiseginae and Loboscelidiinae are believed to be obligate parasitoids of phasmid eggs (Krombein 1983), and as such, they have potential for the biological control of phasmid outbreaks and infestations. Our knowledge of host preference and host specificity is currently insufficient, and further work is required to establish the feasibility of these wasps as control agents.

The rate at which this knowledge is acquired could be increased if studies were made by the large number of people interested in phasmids, from pet keepers through to professional taxonomists. It is hoped that by making knowledge of these enigmatic wasp species freely available online that further research on these groups is encouraged, both by hymenopterists and phasmatologists.

\section{General description}

Purpose: The last comprehensive species catalogue of the Amiseginae and Loboscelidiinae was published in Kimsey and Bohart (1991). The database presented here draws heavily on this work, and brings it up to date through the incorporation of information from subsequent publications and online presentation. Summary statistics are provided in Table 1.

The publication of this data paper is intended not only to publicise the online database, but also to provide a convenient method of citation. The Phasmida Species File Online (Brock 2015) has been cited as a website in multiple fashions with varying dates of 'publication'. A data paper (Chavan and Penev 2011) provides a single method of citation, complete with a Digital Object Identifier (DOI). 
Table 1.

Overview statisitics for the Chrysididae Species File.

\begin{tabular}{|l|l|}
\hline Unique authors & 46 \\
\hline Unique references & 69 \\
\hline Specimen depositories & 36 \\
\hline Speciem records & $347(178$ unique taxa $)$ \\
\hline Genera & $51(36$ valid $)$ \\
\hline Species & $197(187$ valid $)$ \\
\hline Names at all ranks & $252(225$ valid $)$ \\
\hline
\end{tabular}

The database is online at http://chrysididae.speciesfile.org.

Additional information: The Chrysididae SpeciesFile was created by entering the Amiseginae and Loboscelidiinae data provided in Kimsey and Bohart (1991) to create an initial taxonomic hierarchy. Original references were then checked for additional information, and Google Scholar was used to identify publications since 1991. The references of all publications used were checked for additional sources of information. Notes next to references that contain keys and images are made on individual species pages.

\section{Geographic coverage}

Description: The database has global coverage of the two subfamilies, the combined distribution of all taxa covered is shown in Fig. 1

\section{Taxonomic coverage}

Description: The database contains records of all known valid species of Amiseginae and Loboscelidiinae, with full details of synonymy within these subfamilies, both recent and fossil. Full details are given for all type specimens, type species and the first usage of family-group names Fig. 2. Additional specimens from collections have been added from the literature to provide fuller coverage of biogeography. 


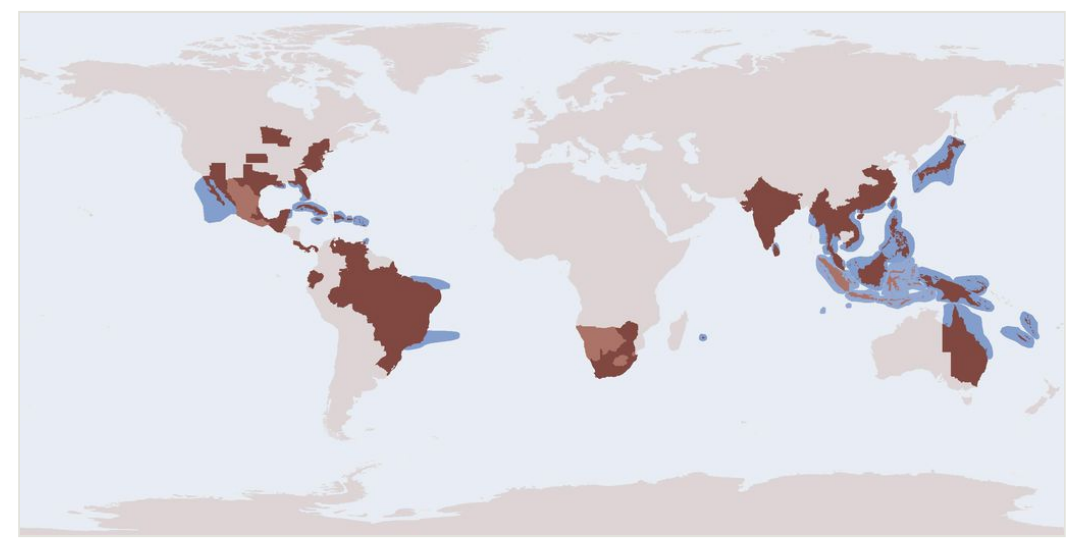

Figure 1.

Distribution of the Amiseginae and Loboscelidinae, generated by the Chrysididae Species File.

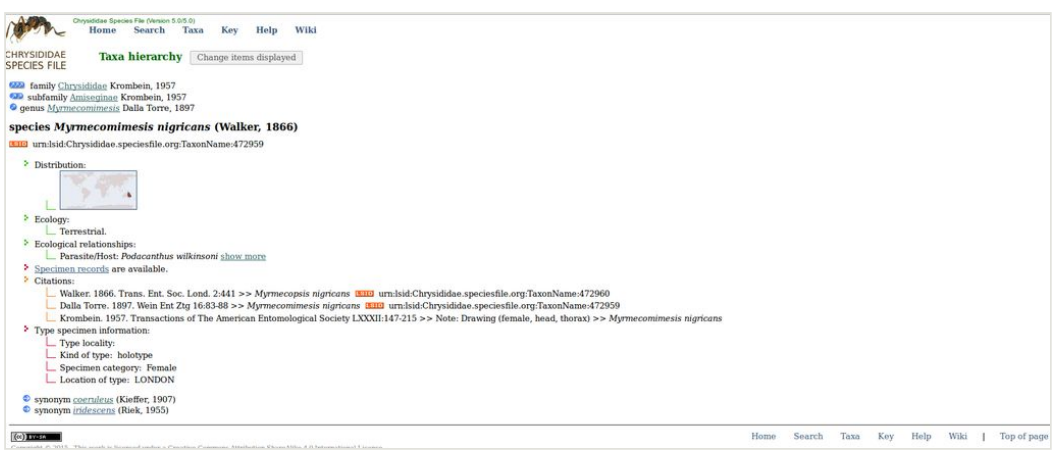

Figure 2.

Taxon page for Myrmecomimesis nigricans showing higher classification, known hosts, a link to specimen records, references, details of the primary type and synonymy.

The Chrysididae Species File can generate distribution maps for any of the taxa it contains. An example showing the overall distribution of the Amiseginae and Loboscelidiinae is shown in Fig. 1

Taxa included:

\begin{tabular}{|l|l|}
\hline Rank & Scientific Name \\
\hline subfamily & Amiseginae \\
\hline subfamily & Loboscelidiinae \\
\hline
\end{tabular}




\section{Traits coverage}

All known host associations are included and referenced. These are displayed on the relevant taxon page (Fig. 2). A complete list can be obtained by using the 'Other taxon in an ecological relationship' option on the 'Search' page.

\section{Usage rights}

Use license: Other

IP rights notes: This work is licensed under a Creative Commons Attribution-ShareAlike 4.0 International License

\section{Data resources}

Data package title: Bibliography of Amiseginae and Loboscelidiinae

Number of data sets: 1

Data set name: Bibliography of Amiseginae and Loboscelidiinae

Download URL: http://dx.doi.org/10.5519/0052040

Data format: plain text

Description: List of works featuring the subfamilies Amiseginae and Loboscelidiinae

\begin{tabular}{|l|l|}
\hline Column label & Column description \\
\hline none & Bibliographic citation \\
\hline
\end{tabular}

\section{Additional information}

\section{Data Sharing}

The use of the SpeciesFile software allows for sharing taxonomic data with Species2000/ Catalogue of Life, and specimen data with the Global Biodiversity Informatics Facility (GBIF). This is achieved through the DarwinCore Archive format, which has become the standard format for sharing biodiversity realted datasets (e.g. Baker et al. 2014) and build on the DarwinCore standard (Wieczorek et al. 2012). The Chrysididae Species File DarwinCore Archive can be downloaded from Baker 2015b. 


\section{Updating}

The species file will be maintained by the author, who will gratefully receive any new papers on these subfamilies via e-mail. At present there are no plans to include the other subfamilies of Chrysididae (Chrysidinae and Cleptinae) unless appropriate editors volunteer their services.

\section{Acknowledgements}

Marilyn Beckman (Species File Software Group, Illinois Natural History Survey) has provided a great deal of assistance in getting the Chrysididae SpeciesFile set up and running.

Philippa Richardson (University College London) provided feedback on the manuscript. I would like to thank the editor and reviewers for their constructive comments on the manuscript.

\section{References}

- $\quad$ Baker E (2015a) Dataset: HyPhas. Resource: DwC-A Export from Chrysididae Species File. NHM Data Portal. Release date: 201512 30. URL: http:// dx.doi.org/10.5519/0052040

- $\quad$ Baker E (2015b) The worldwide status of phasmids (Insecta: Phasmida) as pests of agriculture and forestry, with a generalised theory of phasmid outbreaks. Agriculture and Food Security 4 (22): 1-19. DOI: 10.1186/s40066-015-0040-6

- $\quad$ Baker E, Rycroft S, Smith V (2014) Linking multiple biodiversity informatics platforms with Darwin Core Archives. Biodiversity Data Journal 2: e1039. DOI: $10.3897 /$ bdj.2.e1039

- $\quad$ Bedford GO (1978) Biology and Ecology of the Phasmatodea . Annual Review of Entomology 23 (1): 125-149. DOI: 10.1146/annurev.en.23.010178.001013

- $\quad$ Brock P (2015) Phasmida Species File Online. http://Phasmida.SpeciesFile.org. Accession date: 20151130.

- $\quad$ Chavan V, Penev L (2011) The data paper: a mechanism to incentivize data publishing in biodiversity science. BMC Bioinformatics 12: S2. DOI: 10.1186/1471-2105-12-s15-s2

- $\quad$ Kimsey L, Bohart R (1991) The Chrysidid Wasps of the World. Oxford Science Publications, Oxford, 652 pp. [ISBN 978-0-198-54010-6]

- Krombein KV (1983) Biosystematic Stydies of Ceylonese Wasps, XI: A Monography of the Amiseginae and Loboscelidiinae (Hymenoptera: Chrysididae). Smithsonian Contributions to Zoology 376: 1-79. DOI: 10.5479/si.00810282.376

- Wieczorek J, Bloom D, Guralnick R, Blum S, Döring M, Giovanni R, Robertson T, Vieglais D (2012) Darwin Core: An Evolving Community-Developed Biodiversity Data Standard. PLoS ONE 7 (1): e29715. DOI: 10.1371/journal.pone.0029715 